WS4-A03

\title{
Integrated Log-core Calibrated Approach for Petrophysical and Geomechanical Characterization of Source-rocks
}

\author{
A. Di Matteo* (SGS HORIZON), D. Bonijoly (BRGM), M. Power (SGS ARQS), \\ C. Rigollet (SGS Horizon BV) \& M. Simpson (MAERSK)
}

\section{SUMMARY}

The prediction of mineralogy, TOC, grain density, porosity and gas saturation in organic rich shale is a challenging process that needs to rely on the integration of several measurement methodologies usually performed at different scale and by different disciplines. LECO analysis data can be used to measure the TOC values on core scale. Such values can drive the logs in estimating the TOC on a well scale.

QEMSCAN measurements on core and cuttings provide accurate information about the shale composition. This information can be used, along with the TOC content, routine core data and the petrophysical deterministic analysis, to solve a probabilistic petrophysical model that allows characterizing the mineralogy and the organic content of the shale of interest along the whole well path. Once estimated the rock composition, the Brittleness Index can be estimated by assuming a multi-variable dependence between BI and the shale mineral composition. The BI calculated from the mineral composition can be further calibrated by using site specific rock cuttings and by correlating the BI values based on mineral components with the geomechanical response based on nano-indentation measurements. This methodology will be illustrated during the EAGE WS04 workshop with the Toarcian shale (COUY-1 well, Paris Basin, France). 


\section{Amsterdam '14}

\section{Introduction}

The successful prediction of mineralogy, kerogen, total organic carbon (TOC), grain density, porosity and gas saturation in organic rich shale formations is a complex and challenging process that needs to rely on the integration of several measurement methodologies usually performed at different scale and by different disciplines. Each shale formation, indeed, is unique and conventional well-log interpretations are not always reliable for unconventional source-rocks. Moreover for shale gas formations, besides the favorable key reservoir parameters (e.g. TOC content, thermal maturity, adsorbed and free gas fractions, reservoir thickness, etc.), it is vital to evaluate properly the geomechanical characteristics in order to identify brittle zones suitable for the fracturing process needed for the hydrocarbon production. An evaluation of such mechanical properties (e.g. the brittleness index, BI) can performed by combining density and acoustic impedances (compressional and shear) information. Nevertheless, several attempts have been also made to calculate mechanic rock properties from mineralogy when acoustic datasets are not available or reliable. On this regard, QEMSCAN data have been proved to provide high resolution mineralogical data of shale samples. In this workshop it will be shown an integrated petrophysical approach relying on the combination and calibration of different data sources (i.e. logs, mineralogical and textural data, geomechanical and geochemical measurements) in order to fulfill all the requirements needed to avoid fallacies in the shale formation characterization.

\section{Method}

The proposed approach here presented integrates different data in order to obtain a well-scale shale formation characterization by considering a wire-line log-based petrophysical model driven by core, cuttings and laboratory measurements. Due to the heterogeneity of the different shales, conventional wire-line logs are, in fact, not always reliable to correctly determinate the potential of a organic shale reservoir and advanced logs (e.g. elemental, spectral and full waveform acoustic) are not always available in wells drilled with a purpose different from the organic hydrocarbon production. To optimize the information coming from the conventional wire-line logs, for the determination of the key reservoir parameters and for the detection of suitable frackable zones, the following data classes are considered and integrated: i) Well logs; ii) LECO measurements; iii) Quantitative Electron Microscope Scanning (QEMSCAN); iv) Nano-Indentation characterization.

As a case study, the data gathered for the Toarcian Black Shales interval of Paris Basin (Couy-1 well) are shown in Figure 1 [1,2,3]. Wireline log data are reported in tracks 3-7. As can be seen, the logs show peculiar characteristics in the TOC rich interval ( $328-350 \mathrm{~m} \mathrm{MD})$. Nevertheless, such log characteristics are not easily and quantitatively relatable to the TOC content. In particular, it can be noted that the Uranium content (track 5, URAN curve) is not showing, as expected [4], a significant correlation with the TOC content (shown in track 11 by the TOC curve, with values above 3\% highlighted with a green shading). The TOC curve depicted has been obtained via LECO analysis. In track 8, the yellow shading is showing, as an example, the TOC presence deducted by using the Resistivity/Density $\Delta \operatorname{logR}$ technique [4 and references therein], while in track 9 the TOC red curve is depicting the final result achieved by weighting and averaging the different $\Delta \log R$ techniques (based on Neutron, NPHI, Density, RHOB, Sonic, LST, and Resistivity, ILD and ILM, logs). In track 9, the Pyrite content determined via QEMSCAM measurements is also shown. As expected, an increase in Pyrite is related to the higher TOC values due to their strong geochemical relationship [4]. In track 10 the main mineralogical components (retrieved through QEMSCAN) are reported for the TOC rich interval, while in track 11 the QEMSCAN-based Clay composition is showed. Finally, in track 12, the brittleness index calculated from the mineral composition [5] is shown. 


\section{Amsterdam |'14}

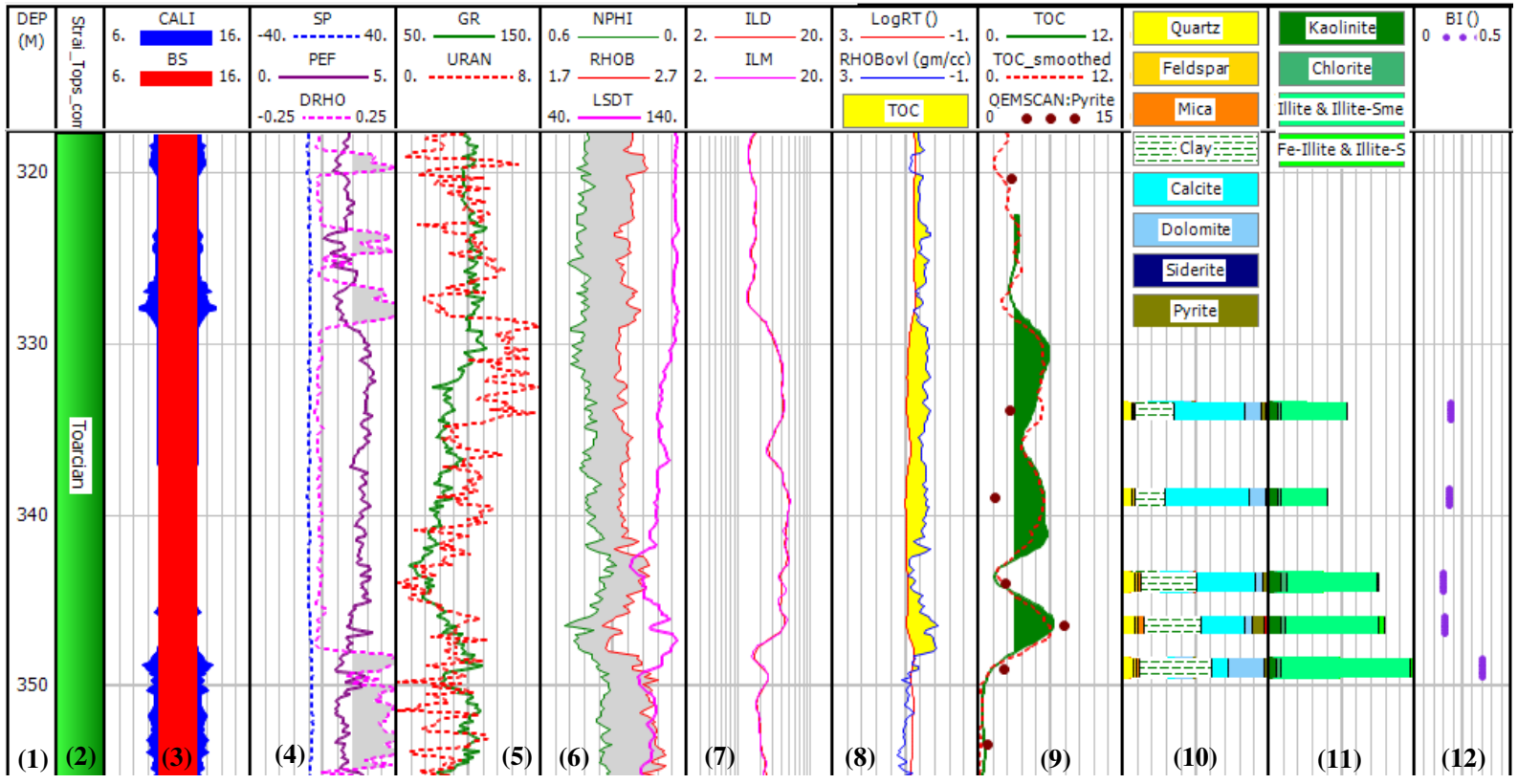

Figure 1 Data overview and Petrophysical evaluations for the Couy-1 organic rich shale Toarcian interval. In particular: in track 9, the TOC values (from both laboratory and log analysis) are shown; in track 12, the BI (calculated from the mineral composition) is depicted.

\section{Conclusion}

As a conclusion, a plausible integrated workflow, based on the combination and calibration of different data sources, is below proposed with the aim to obtain a reliable well-scale organic rich shale formation characterization.

LECO analysis data can be used to measure the TOC weight percent values on a core scale. Such values can drive the logs in estimating the Total Organic Carbon on a well scale.

QEMSCAN measurements on core and cuttings provide accurate information about the shale mineral composition [6]. This information can be used, along with the TOC content, routine core data and the petrophysical deterministic analysis, to solve a probabilistic petrophysical model that allows characterizing the mineralogy and the organic content of the shale of interest along the whole well path.

Once estimated the rock composition, the brittleness index can be estimated by assuming a multivariable dependence between $\mathrm{BI}$ and the shale mineral composition. To obtain robust results, the brittleness index calculated from the mineral composition can be further calibrated by using site specific rock cuttings and by correlating the BI values based on mineral components with the geomechanical response based on Nano-Indentation measurements [7].

\section{References}

[1] Pradier, B. and Gauthier, B. (1987) Etude préliminaire de la matière organique sédimentaire. Document du BRGM $n^{\circ}$ 136, Lorenz \& Weber ed., pp. 103-118.

[2] Disnar, J.R. and Gauthier, B. (1987) Composés organiques volatils dans la série sédimentaire : influence des circulations aqueuses. Document du BRGM $n^{\circ}$ 136, Lorenz \& Weber ed., pp. 119-123. [3] Lasseur et al. (2011) 3D geometry, paleogeography and facies distribution of the Paris Basin Lias deposits (France), BRGM/RP-59611-FR.

[4] Passey et al. (2010) From oil-Prone Source Rock to Gas-Producing Shale Reservoir, SPE 131350. [5] Slatt (2011) Important Geological Properties of Unconventional Resource Shales, Cent. Eur. J. Geosci. 1/14, 2011.

[6] Power et al. (2014) The role of mineralogy in the facies heterogeneity characterization of organic rich shaleWS04, $76^{\text {th }}$ EAGE Conference \& Exhibition.

[7] De Block et al. (2014) Shale geomechanics: a nanoindentation application. $76^{\text {th }}$ EAGE Conference \& Exhibition. 